\title{
Plant-mediated effects in the Brassicaceae on the performance and behaviour of parasitoids
}

\author{
Rieta Gols · Jeffrey A. Harvey
}

Received: 28 January 2008/ Accepted: 14 June 2008/Published online: 9 July 2008

(C) The Author(s) 2008

\begin{abstract}
Direct and indirect plant defences are well studied, particularly in the Brassicaceae. Glucosinolates (GS) are secondary plant compounds characteristic in this plant family. They play an important role in defence against herbivores and pathogens. Insect herbivores that are specialists on brassicaceous plant species have evolved adaptations to excrete or detoxify GS. Other insect herbivores may even sequester GS and employ them as defence against their own antagonists, such as predators. Moreover, high levels of GS in the food plants of non-sequestering herbivores can negatively affect the growth and survival of their parasitoids. In addition to allelochemicals, plants produce volatile chemicals when damaged by herbivores. These herbivore induced plant volatiles (HIPV) have been demonstrated to play an important role in foraging behaviour of insect parasitoids. In addition, biosynthetic pathways involved in the production of HIPV are being unraveled using the model plant Arabidopsis thialiana. However, the majority of studies
\end{abstract}

R. Gols ( $\bowtie)$

Laboratory of Entomology, Wageningen University, P.O. Box 8031, $6700 \mathrm{EH}$ Wageningen, The Netherlands e-mail: rieta.gols@wur.nl

J. A. Harvey

Department of Multitrophic Interactions, Netherlands Institute of Ecology, P.O. Box 40, 6666 ZG Heteren, The Netherlands investigating the attractiveness of HIPV to parasitoids are based on experiments mainly using crop plant species in which defence traits may have changed through artificial selection. Field studies with both cultivated and wild crucifers, the latter in which defence traits are intact, are necessary to reveal the relative importance of direct and indirect plant defence strategies on parasitoid and plant fitness. Future research should also consider the potential conflict between direct and indirect plant defences when studying the evolution of plant defences against insect herbivory.

Keywords Crucifers - Direct defence · Glucosinolates · Indirect defence · Herbivore-induced plant volatiles
Abbreviations
GS Glucosinolates
HIPV Herbivore induced plant volatiles

\section{Introduction}

Plants have evolved several strategies to reduce or prevent insect herbivory. These defence strategies can be divided into direct and indirect defences. Direct defences have a negative impact on development and behaviour of the herbivore, whereas indirect defences enhance the ability of natural enemies such as parasitoids and predators to exploit herbivores on the plant. 
Plant defences often involve the production of secondary chemical compounds (=allelochemicals) that can have negative effects on the development and survival of insect herbivores. Plant allelolochemicals are often phylogenetically conserved in specific plant families or genera, such as glucosinolates (hereafter GS) in the Brassicaceae (Rosenthal and Berenbaum 1992; Schoonhoven et al. 2005). Chemicals that promote the effectiveness of natural enemies involve volatile compounds that are produced in response to herbivore feeding damage, so-called herbivore induced-plant volatiles (HIPV). These HIPV are known to be attractive to parasitoids and predators of arthropod herbivores (Dicke 1999a; Turlings et al. 2002).

Unlike predators that may need to feed on several prey to reach maturity, the development of parasitoids is dependent on the finite resources contained in a single host individual. Arthropod herbivores obtain their nutrition directly from their food plants. Consequently, parasitoids of these herbivores obtain their nutrition indirectly from the plants (Bottrell et al. 1998; Turlings and Benrey 1998). It has been shown that plant allelochemicals may not only negatively affect the development of herbivores but also that of their parasitoids (Hunter 2003; Ode 2006). Furthermore, parasitoid reproductive success is closely correlated with the female's ability to find hosts (Godfray 1994); therefore, parasitoids have evolved efficient foraging strategies to locate hosts in often complex environments. HIPV have been demonstrated to play an important role in host-finding behaviour of parasitoids that attack larval stages of insect herbivores (Dicke 1999a; Turlings et al. 2002). Thus, plant-mediated effects on parasitoid performance and behaviour can act negatively through the production of allelochemicals and positively through the production of volatile attractants. However, as will be discussed, these two plant defence traits are not necessarily mutually exclusive (Havill and Raffa 2000; Hunter 2003).

The Brassicaceae family contains important crops such as cabbages (Brassica oleracea L.) and oilseeds (B. nigra L., B. napus L. etc.). A number of insect herbivores associated with these plants have become serious pests and as a result the interaction between these insects and their food plants is well studied. Parasitoid species are often restricted to a narrow range of host species, which has promoted the use of parasitoids to control insect pests in agricultural systems. Many studies have investigated the importance of HIPV as foraging cues for parasitoids that attack hosts feeding on brassicaceous plant species. However, little is known about the effect of food-plant quality on parasitoid performance in this plant family. After tissue damage, myrosinases catalyse the hydrolysis of GS into (iso)thiocyanates and nitriles. A vast amount of literature has demonstrated that GS hydrolysis products are mobilised in defence against insect herbivores (Chew 1988; Rask et al. 2000). The volatile hydrolysis products can act as repellents, whereas the GS present in the food may significantly alter the physiology and development of some herbivores, through reduced growth rates, smaller adult size and increased mortality. Insect herbivores that mainly feed on brassicaceous plant species have evolved special adaptations to excrete and/ or detoxify GS (Ratzka et al. 2002; Wittstock et al. 2004). Moreover, some insects sequester GS and employ them as defence against their own antagonists (Müller et al. 2001; Aliabadi et al. 2002). The effect of brassicaceous plant species on the performance and behaviour of insect parasitoids is the topic of this review.

First, we examine the effect of brassicaceous food plants on the development of hosts and their parasitoids. We briefly describe the effects of sequestration of GS by some insect herbivores on organisms in the third trophic level. Because only a few studies have investigated the effect of GS-sequestration on organisms in the third trophic level, we examine this in both parasitoids and predators. Second, we review studies reporting on the attraction of parasitoids to HIPV. Furthermore, special attention is paid to the model plant Arabidopsis thialiana L. and its role in elucidating mechanisms underlying tritrophic interactions. Finally, we discuss the fact that most studies investigating tritrophic interactions in brassicaceous plant species use cultivated varieties. Artificial selection may have changed the chemistry of crop plants in such a way that the performance of herbivores and their parasitoids differ on cultivated and wild conspecific plants.

\section{Direct plant defence: are herbivore and parasitoid performance differentially affected by plant quality?}

Relatively few studies have investigated the effects of secondary plant chemistry mediated through the host on parasitoid performance (Harvey 2005; Ode 2006). 
Parasitoids of herbivores feeding on GS-containing plants may be negatively affected by plant-derived compounds that are stored in the haemolymph or other body tissues of the herbivore. Furthermore, the feeding strategy of the parasitoid larva may determine to what extent the parasitoid offspring are exposed to plant allelochemicals (Harvey and Strand 2002). For example, parasitoid species whose larvae are obligate tissue feeders and have to consume the host completely before pupation are likely to be exposed to plant-derived compounds that are stored in the host's body tissues or in the gut. Alternatively, parasitoids that selectively feed on haemolymph and fat body and pupate externally from the host larva may avoid exposure to harmful plant-derived compounds. Parasitoid performance may also be compromised due to reduced size or quality of the host itself. Furthermore, the efficiency of the host immune response may be reduced when the host is feeding on more toxic plant genotypes or species (Karimzadeh and Wright 2008), which in turn may increase parasitism success. In the following two sections, we will examine studies that have investigated the performance of parasitoids on hosts feeding on different species and populations of brassicaceous plants.

Effects of interspecific variation in plant quality on parasitoid performance

Table 1 provides an overview of studies that have investigated the performance of both herbivores and parasitoids reared on different brassicaceous plant species. Generalist herbivores, which can feed on plant species in several plant families, are usually more sensitive to plant allelochemicals than specialist herbivores, which are adapted to feed on plants containing specific phytotoxins, such as GS (Blau et al. 1978). Likewise, parasitoids attacking generalist herbivores have been shown to be more strongly affected by the herbivore's diet than parasitoids that attack hosts only feeding on brassicaceous plant species (Sznajder and Harvey 2003; Gols et al. 2008c). Specialist herbivores have evolved efficient GS detoxification mechanisms (Ratzka et al. 2002; Wittstock et al. 2004; Agerbirk et al. 2006). Consequently, parasitoids of specialist herbivores may be exposed to only low levels of GS or their breakdown products. However, the development of parasitoids of hosts that are specialised on brassicaceous plant species have also been shown to differ with host plant quality (Benrey et al. 1998; Harvey et al. 2003; Sznajder and Harvey 2003; Gols et al. 2007). Negative plant-mediated effects can even affect hyperparasitoids (parasitoids that develop in other parasitoids) in the fourth trophic level (Harvey et al. 2003; Soler et al. 2005). One factor to consider is that brassicaceous plants contain other allelochemicals in addition to GS. For example, cardenolides in the annual weed Erysimum cheiranthoides L. are feeding deterrents to larvae of specialists such as Pieris rapae L. (Renwick 2001). Related species, like Bunias orientalis L, are actually toxic to specialists in the Pieridae and this leads to precocious death of their parasitoids. However, the main GS in B. orientalis is sinalbin (4-hydroxybenzyl-glucosinolate), which is not toxic to pierids, thus indicating the presence of some other, as of yet unidentified toxin (J.A. Harvey, unpublished).

Quite often, the performance of the host and its parasitoid are positively correlated (Benrey et al. 1998; Harvey et al. 2003; Sznajder and Harvey 2003), although the adverse effects of food plant characteristics on insect performance are usually less pronounced in the parasitoid than in the herbivore. Secretion and/or detoxification of plant allelochemicals by the host may dilute the effect of these compounds on the development of the parasitoid. In addition, the feeding strategy of the parasitoid larva may influence the extent to which parasitoid offspring are exposed to the adverse effects of plant-derived compounds. For example, Gols et al. (2008b) found that the haemolymph-feeding parasitoid Cotesia glomerata L. (Fig. 1b), developed equally well on hosts feeding on Sinapis arvensis L. and Brassica nigra, whereas its host, Pieris brassicae L., was significantly smaller and took longer to complete development on S. arvensis. By contrast, Karowe and Schoonhoven (1992) showed that $C$. glomerata attained higher biomass and developed faster when parasitizing P. brassicae caterpillars that feed on Tropaeolum majus L. than on B. napus and B. oleracea, whereas its host $P$. brassicae performed better on the latter two food plants. Tropaeolum majus contains GS, although it is not a member of the Brassicaceae. Differences in nutritional requirements and/or sensitivity to secondary plant metabolites may explain the differential performance of the host and its parasitoid. 


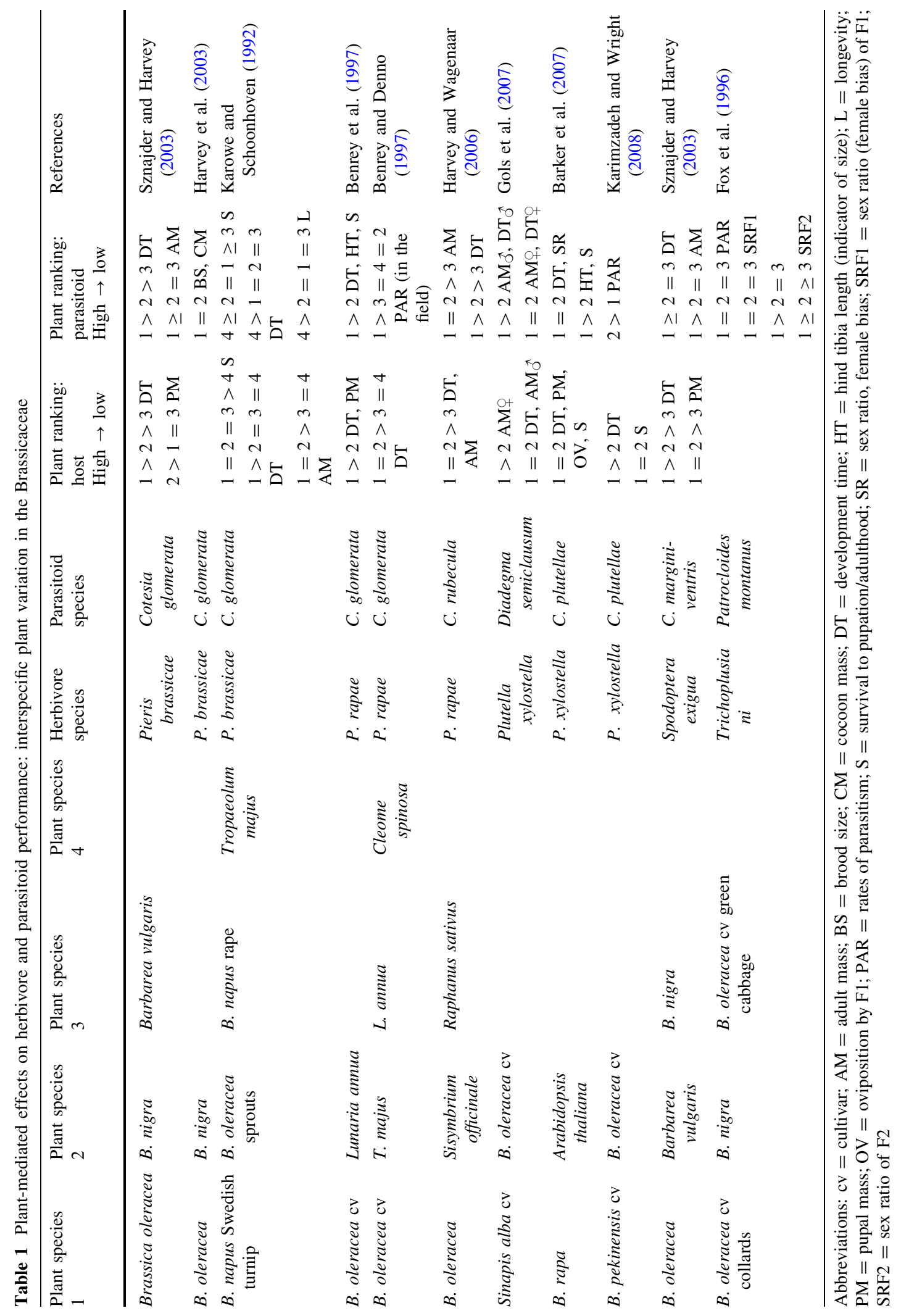



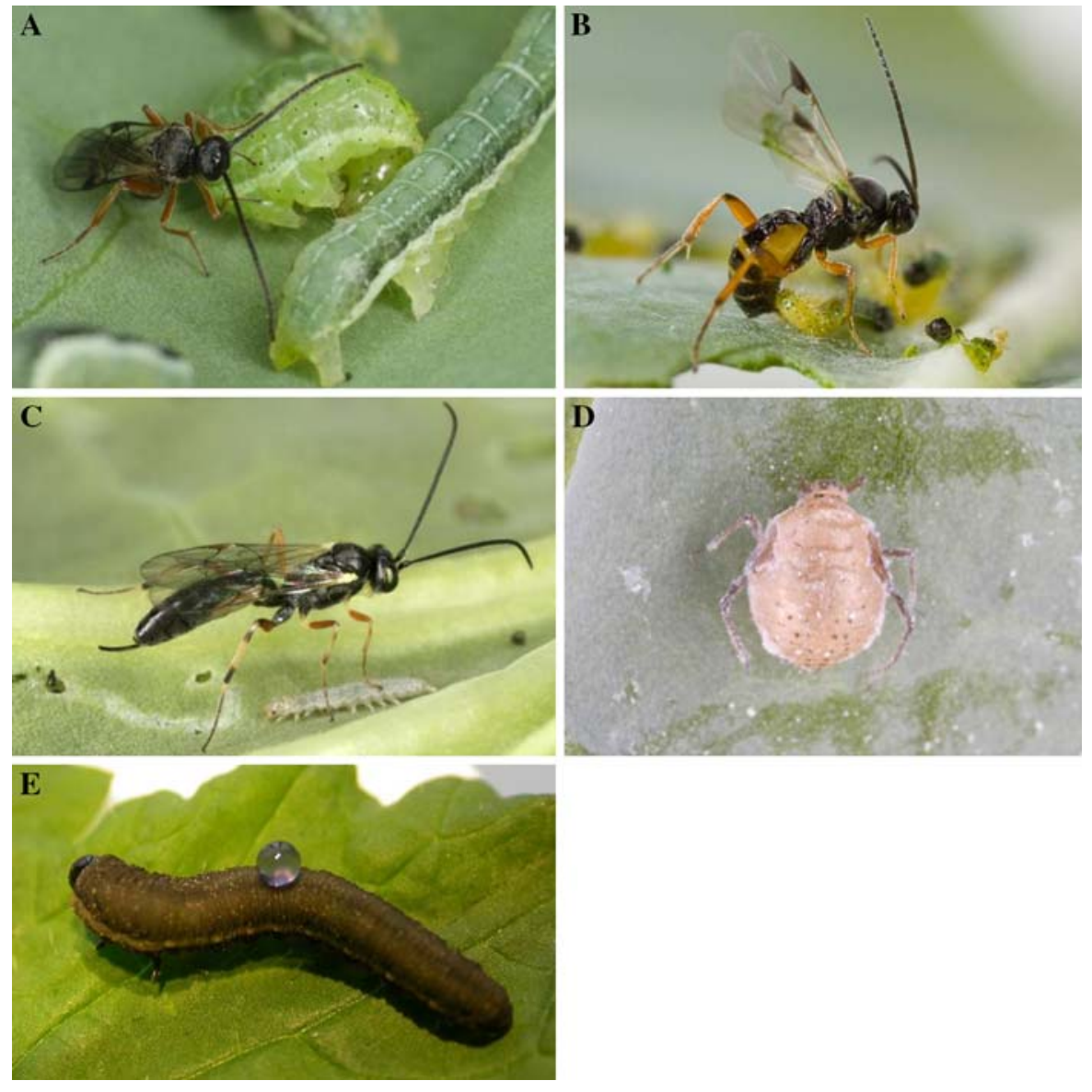

Fig. 1 Several species of insect herbivores and parasitoids used in research on tritrophic interactions involving brassicaceous plant species. (a) Microplitis mediator is a fairly specialised solitary endoparasitoid of hosts that can feed on plants in several plant families. Here, a female is ovipositing in a larva of the cabbage moth, Mamestra brassicae. (b) Cotesia glomerata is also a fairly specialised gregarious larval endoparasitoid that attacks young larvae of pierid hosts. Here a female is parasitising a Pieris brassicae larva. (c) Diadegma semiclausum is a specialist solitary larval endoparasitoid of the diamondback moth, Plutella xylostella. This parasitoid can

Effects of intraspecific variation in plant quality on parasitoid performance

Several studies have shown that GS are variably expressed in different cultivars and wild populations of B. oleracea. Levels of GS are generally lower in B. oleracea cultivars than in wild populations (Mithen et al. 1995; Kushad et al. 1999; Rosa 1999; Moyes et al. 2000; Gols et al. 2008c). Brassica oleracea is an interesting plant species with respect to foliar GS composition in leaf tissues. The leaf tissues of this plant attack all four larval stages of its host. (d) A mummified aphid, Brevicoryne brassicae, containing a pupa of its parasitoid, Diaeretiella rapae. This parasitoid is a generalist and is known to attack a number of aphids including Myzus persicae and Br. brassicae. (e) A 'bleeding' larva of the sawfly, Athalia rosae. Larvae of A. rosae sequester GS from the food plant in their haemolymph and easily bleed when touched by selfrupturing the integument. This bleeding has been shown to deter predators of this herbivores. Photographs are printed with permission of Tibor Bukovinszky, Hans Smid and Caroline Müller

species sometimes contain up to ten different GS compounds, of which individual concentrations can differ considerably among different cultivars and wild populations. This is in contrast to other plant species in which one GS dominates the GS profile (e.g., sinigrin or 2-propenyl glucosinolate in B. nigra and sinalbin in $S$. alba L.). Wild populations of B. oleracea, which grow naturally along the Atlantic coastlines of England and France, differ considerably in constitutive and inducible levels of GS (Mithen et al. 1995; Moyes et al. 2000; Gols et al. 2008c). Aliphatic GS (GS 
derived from methionine) concentrations differed among the wild populations, but did not change in response to herbivore feeding (Gols et al. 2008a). Concentrations of indole GS (GS derived from tryptophan) have been demonstrated to be low in undamaged plants, but are differentially induced in response to feeding damage (Gols et al. 2008a).

The performance of herbivores feeding on plants differing in foliar GS content has been well studied (Hopkins et al. 1998; Li et al. 2000; Agrawal and Kurashige 2003). Plants with high levels of GS can reduce the performance of both generalist and specialist herbivores, although the effects of GS on specialists are usually less pronounced ( $\mathrm{Li}$ et al. 2000; Gols et al. 2008a). Only a few papers have reported the effects of intraspecific variation in GS content on parasitoid performance (Table 2). For example, P. rapae developed faster and grew larger on one of three wild B. oleracea populations with the lowest level of inducible GS (Gols et al. 2008c). Development of both the solitary larval endoparasitoid, C. rubecula Marshall, and the gregarious pupal parasitoid, Pteromalus puparum L., closely reflected plant quality for P. rapae feeding on the wild $B$. oleracea populations (Harvey et al. 2007a; Gols et al. 2008c). Interestingly, the generalist herbivore Mamestra brassicae L., and its fairly specialised larval endoparasitoid, Microplitis mediator Haliday (Fig. 1a), developed more poorly on wild cabbage populations with the highest levels of constitutive GS (Gols et al. 2008c). Performance of the specialist herbivore, $P$. rapae, appeared to be affected by inducible indole GS in its food plant, whereas the generalist, $M$. brassicae, responded negatively to high overall GS concentrations. These results reveal variation in the differential effects of plant quality, possibly mediated through GS, on the development of oligophagous and polyphagous herbivores and their parasitoids.

Above, we referred to studies where food plant quality was compared in different strains or populations of the same species. However, the quality of an individual plant may change in response to a suite of biotic factors such as pathogen infections and herbivore feeding (Agrawal 1999), as well as abiotic factors such as nutrient levels and light conditions (Schoonhoven et al. 2005). Over the course of a growing season, the quality of leaf tissues may change due in part to changes in abiotic conditions, leading to concomitant effects on herbivore-natural enemy interactions. This is particularly important for insects that have more than a single generation over the course of a year. Later generations of herbivores may develop on plants that differ profoundly in terms of their defence chemistry from the natal plants of their parents. Current knowledge about the effects of GS on insect development in a multitrophic framework has often been based on experiments performed during a single time frame. For instance, the development of three cohorts of Plutella xylostella L. and its endoparasitoid Diadegma semiclausum Hellén (Fig. 1c) differed significantly when reared on cultivated B. oleracea and S. alba plants grown over the course of a single summer and autumn season (Gols et al. 2007). Although the plants were grown under strictly similar conditions in a greenhouse, foliar levels of GS changed quite dramatically from one experiment to another, with significant effects on the development of the herbivore and its parasitoid. This suggests that conditions in nature, which are not controlled, but which may change profoundly over quite short time scales, may affect associated consumers even more. Certainly, this is an understudied area that merits further investigation.

Thus far, we have described the results of studies investigating herbivore-parasitoid interactions in the above-ground compartment of a plant system. However, single plant, herbivore and parasitoid associations constitute only a small part of a complex above- and below-ground environment. Feeding damage caused by root and shoot herbivores may lead to both qualitative and quantitative changes in root and shoot tissues that are not necessarily correlated, due to differing effects of herbivory on primary and secondary metabolites in the below- and above-ground domains (Masters and Brown 1997; Bezemer and van Dam 2005; van Dam et al. 2008). These changes in above- and below-ground plant organs may not only affect the development of herbivores in the two spatially separated compartments, but also higher trophic level organisms associated with these herbivores. Low levels of herbivory by larvae of the cabbage root fly Delia radicum $\mathrm{L}$. negatively influenced development of both the foliar herbivore $P$. brassicae and its parasitoid C. glomerata when reared on B. nigra plants (Soler et al. 2005). The adverse effects of root herbivory were even transmitted to the fourth trophic level; the hyperparasitoid Lysibia nana Gravenhorst was significantly smaller when emerging from 


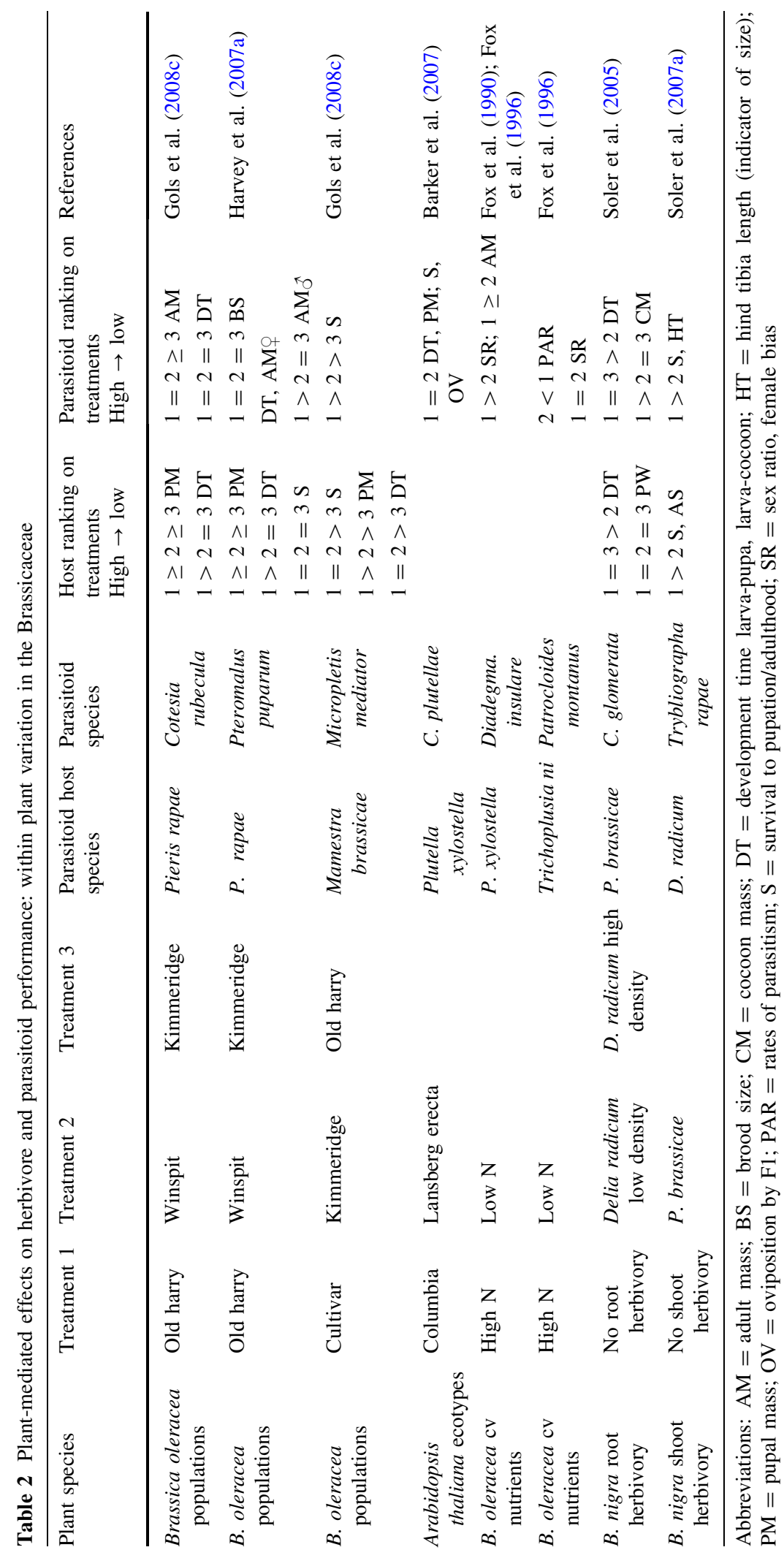


C. glomerata cocoons originating from plants exposed to root herbivory by $D$. radicum (Soler et al. 2005). The authors argued that increased concentrations of the GS sinigrin in foliar tissues of plants exposed to root herbivory could be responsible for the reduced performance of the above-ground insects. In a reciprocal study, Soler et al. (2007a) investigated the effect of shoot herbivory on performance of D. radicum and its larval endoparasitoid Trybiographa rapae West. Size and survival in both $D$. radicum and $T$. rapae were negatively affected when reared on plants whose shoots had been previously damaged by $P$. brassicae larvae, compared with undamaged control plants (Soler et al. 2007a). Shoot herbivory did not affect nitrogen concentrations in the roots. However, levels of the indole GS, glucobrassicin (3-indolylmethyl glucosinolate) and neoglucobrassicin (1-methoxy-3indolylmethyl glucosinolate) increased significantly in the secondary roots of plants in response to $P$. brassicae feeding. These studies show that by focusing exclusively on the above-ground environment, our understanding of the processes that influence multitrophic interactions, e.g., between plants, herbivore and parasitoids, is likely to be incomplete (Harvey 2005).

\section{The effect of sequestration of GS by insect herbivores on predators and parasitoids}

Specialised insects feeding on brassicaceous plant species have not only evolved adaptations to cope with the adverse effects of GS, but some insects actively sequester GS in their haemolymph or other body tissues and use them for their own defence. For example, the sawfly Athalia rosae L., which mainly feeds on GS-containing plants, concentrates GS obtained from the food plant in its haemolymph (for a detailed review see Müller this issue-a). The integument of A. rosae larvae is easily disrupted when touched and haemolymph is released from the wound. This 'easy bleeding' (Fig. 1e) has been shown to deter predators such as lizards (Vlieger et al. 2004), ants (Müller et al. 2002) and predatory wasps like Vespula vulgaris L. (Müller and Brakefield 2003).

The harlequin bug Murgantia histrionica Hahn also sequesters GS from its food plant and is distasteful to several species of bird predators (Aliabadi et al. 2002). The possibility of sequestration of GS by immature stages of Pieris species has generated controversy. An early study (Aplin et al. 1975) reported on the sequestration of GS by larvae and pupae of $P$. rapae and $P$. brassicae. However, a recent study by Müller et al. (2003), in which more advanced GS analysis techniques were used, found that GS could not be detected in body tissues or haemolymph of $P$. rapae and $P$. brassicae larvae that had been feeding on GS-containing food plants. Interestingly, Wiklund and Järvi (1982), demonstrated that starlings (Sturnus vulgaris L.) rejected P. brassicae caterpillars as food. Moreover, Rayor et al. (2007) reported that paper wasps (Polistes dominulus Christ) spent more time handling $P$. napi L. caterpillars that had been feeding on Erysimum cheiranthoides, Tropaeolum majus and B. nigra, crucifers with high levels of potentially deterrent GS, than $P$. napi caterpillars that had been feeding on a less toxic cabbage cultivar (B. oleracea capitata). Extended handling by the wasp involved removal of the gut, suggesting that, although GS might not be sequestered, the presence of plant tissue material in the gut reduces foraging efficiency. It cannot be excluded that secondary compounds other than GS are responsible for the observed extended handling behaviour.

GS become toxic through a process of catalytic hydrolysis by myrosinase enzymes, which are stored in cytoplasm of specialised myrosin cells that are scattered throughout the plant tissues (Mithen 2001). Degradation of GS only occurs after cell rupture leading to the production of nitriles, isothiocyanates, thiocyanates and oxazolidinethiones. This myrosinase-GS defence mechanism is mirrored in the aphids Brevicoryne brassicae L. (abbreviated into Br. brassicae) and Lipaphis erysimi Kaltenbach (Bridges et al. 2002). Both aphid species sequester GS from phloem sap in their host plant, but the enzyme myrosinase is endogenous to the aphids (Bridges et al. 2002; Kazana et al. 2007). When predatory larvae of the ladybird beetle Adalia bipunctata L. and the hoverfly Episyrphus balteatus de Geer fed on either Br. brassicae or Myzus persicae Sulzer, survival was significantly lower on Br. brassicae (Francis et al. 2001a; Vanhaelen et al. 2002). Myzus persicae does not sequester GS, nor does it possess endogenous myrosinase. 
Moreover, for both predator species, survival depended on the host plant species on which $B r$. brassicae had been feeding previously. Survival of the predators was equally low on $S$. alba and $B$. nigra, but was higher when Br. brassicae had been feeding on B. napus, which contains much lower levels of total GS than the other two plant species. By contrast, survival of A. bipunctata was very high when the prey was $M$. persicae, irrespective of the food plant species on which the aphid had been feeding (Francis et al. 2001a). Chemical identification of GS and related degradation products in both aphid species revealed very low levels of GS and no degradation products in $M$. persicae, and very high levels of GS and isothiocyanates in Br. brassicae (Francis et al. 2001a). In a separate study Francis et al. (2001b) also found that other fitness correlates such as development time and adult body mass were not affected by food plant species of $M$. persicae. However, fecundity of $A$. bipunctata females that had been reared from $M$. persicae on $S$. alba was significantly lower than that of the same aphid species reared on B. napus with low GS levels. In contrast, this defence mechanism is not effective against Diaeretiella rapae McIntosh (Fig. 1d), a parasitoid of aphids feeding on several Brassica species. This parasitoid has a greater innate preference for $B r$. brassicae than for $M$. persicae, but differences in performance when reared on the two aphid species were found to be minimal (Blande et al. 2004).

These results demonstrate the effectiveness of sequestration of food-derived GS by specialised herbivores against generalist natural enemies. In addition, the effectiveness of anti-predator activity often depends on the host plant on which the herbivore has been feeding. Plant-mediated effects against natural enemies are also present in less well adapted herbivores, but their effects can be compromised by the reduced performance of the herbivore itself.

\section{Indirect defence: the production of volatile chemicals that attract parasitoids of herbivores feeding on brassicaceous plant species}

Attempts have been made to elucidate which specific volatile plant compounds play a role in the attraction of parasitoids and predators to their host plant (Dicke et al. 1990; de Boer and Dicke 2004; Shiojiri et al. 2006b; Halitschke et al. 2008). In addition, biosynthetic pathways involved in the production of the volatiles are being unraveled (Dicke and van Poecke 2002; Arimura et al. 2008). Brassica cultivars, especially those of B. oleracea, are well studied with respect to HIPV and their attractiveness to the herbivore's natural enemies (see Table 3). All parasitoid species in Table 3 have been shown to discriminate between volatiles from damaged and undamaged plants and most of them are attracted more to HIPV than to volatiles emitted by artificially damaged plants. However, only a few parasitoid species prefer volatiles from host-damaged plants over plants damaged by non-host species (Geervliet et al. 1996; Shiojiri et al. 2000), although some parasitoid species can learn to differentiate between volatiles induced by host and non-host herbivores (Geervliet et al. 1998). These results indicate that volatile emissions by species in the Brassicaceae are very similar when plants are damaged by different herbivores as has been demonstrated in earlier studies (Blaakmeer et al. 1994; Geervliet et al. 1997). Consequently, the parasitoids may be unable to detect these minor differences.

Among the volatile chemicals involved in hostplant location by parasitoids, green leaf volatiles and terpenoids are assumed to play an important role, because their levels change in response to herbivore feeding. However, these two groups of chemicals are ubiquitously produced in the plant kingdom and thus may not always provide reliable cues that reveal the identity of the host-plant complex. Alternatively, the identity of the plant and its attacker can be determined based on differences in the relative concentrations of compounds in the volatile blends (de Boer et al. 2004). Physiological constraints usually limit the number of different host species that can be parasitised by a larval endoparasitoid, but herbivorous hosts specialised on brassicaceous plants can feed on a range of different plant species. Surprisingly, few studies have compared the composition of HIPV and their attractiveness to parasitoids in different brassicaceous plant species (Takabayashi et al. 1998; Bukovinszky et al. 2005).

Many species in the Brassicaceae are short-lived annuals and often grow in disturbed areas associated with human activity (Feeny 1977). Therefore, herbivores and associated parasitoids have to find these 


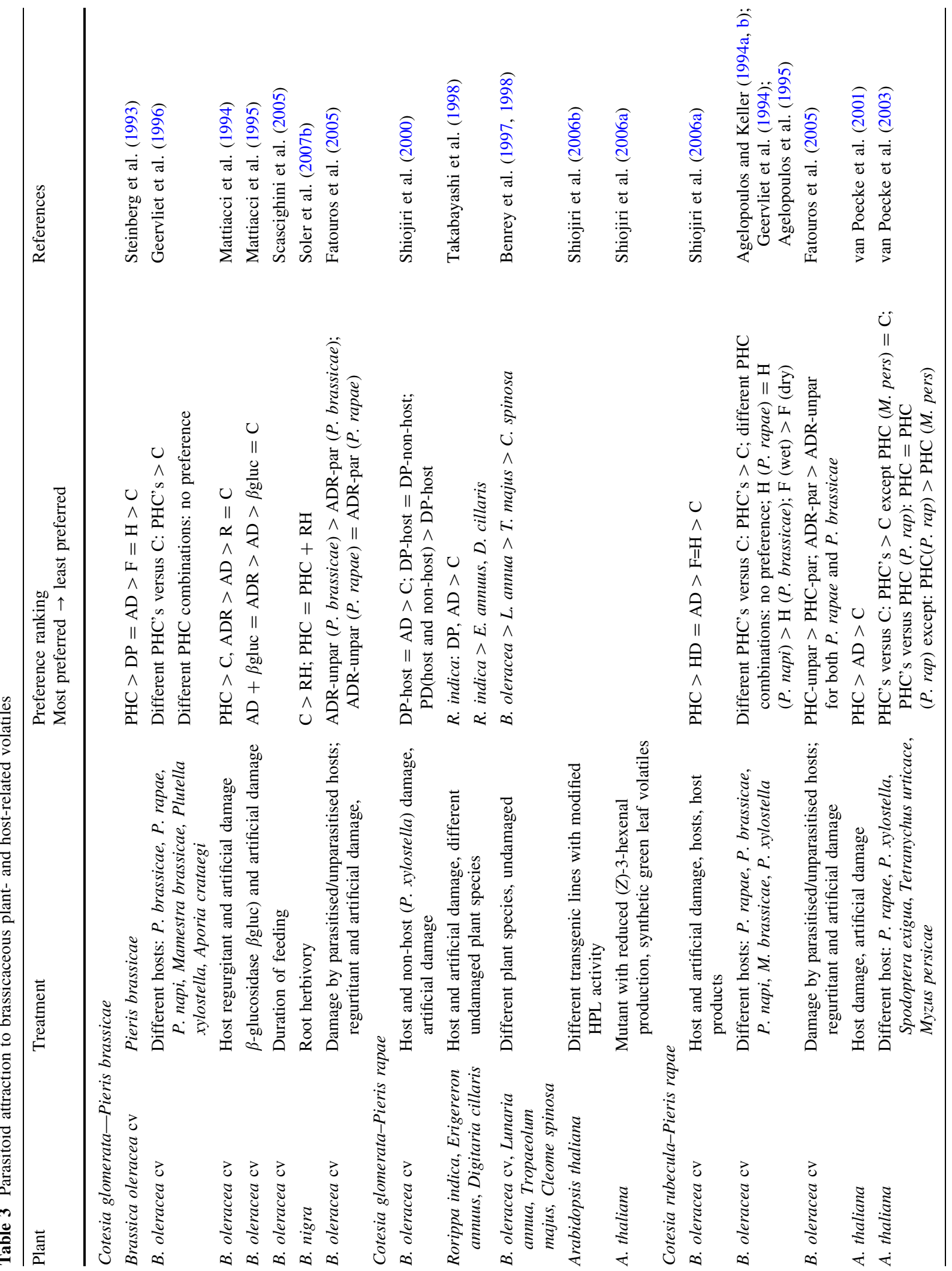




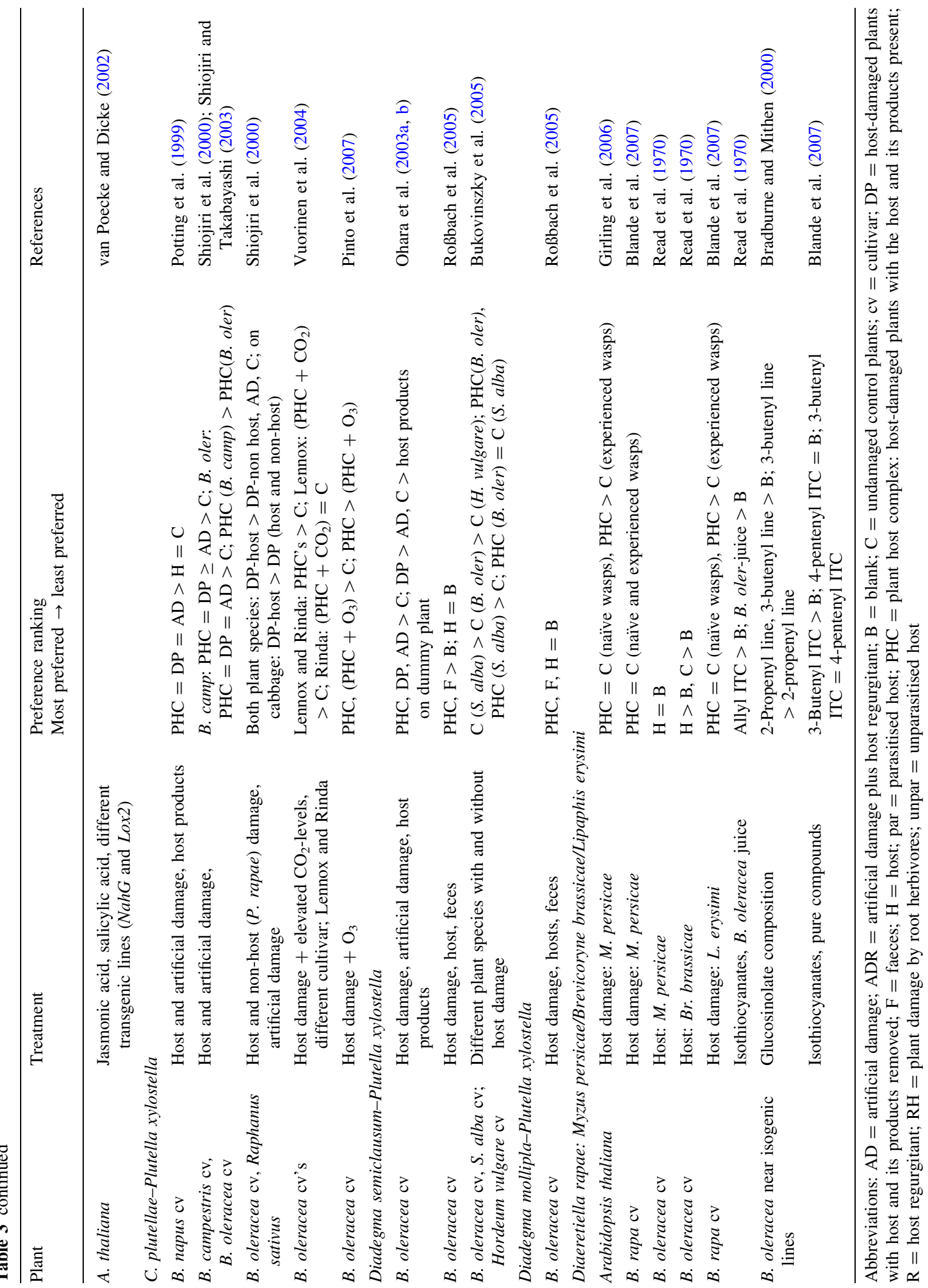


plants growing in patches that are often spatially and temporally unpredictable. In addition, different generations of these insects may grow on different host plant species. Therefore, it is critically important for parasitoid females to be able to recognise a range of host food plants that may differ considerably in the composition of their volatile emissions when damaged by hosts. Volatile GS hydrolysis products seem obvious candidates as reliable signals in brassicaceous plant species. Attraction to GS hydrolysis products has thus far only been demonstrated in the aphid parasitoid D. rapae (Read et al. 1970; Bradburne and Mithen 2000; Blande et al. 2007).

\section{Plant-herbivore-parasitoid interactions in domesticated and wild Brassicaceae}

In the Brassicaceae, domestication has given rise to several important crops such as cabbages (B. oleracea, B. napus), oilseeds (B. napus, B. juncea and B. rapa L.) and mustard condiments (B. nigra, S. alba). Cultivation has generally been aimed at enhancing a trait or a suite of traits in the plant, such as the production of specific plant organs or structures. Importantly, this may or may not be compatible with direct or indirect defences. For instance, one of the most important traits in vegetable crops is their taste. Selection on this trait may be in direct conflict with direct defence depending on whether this trait is emphasised (e.g., mustard condiments) or not (e.g., cabbage). As a consequence of artificial selection, levels of primary and secondary plant compounds in crop plants may have changed in such a way that these plants have become more susceptible to insect attack. For example, GS in B. oleracea cultivars are often reduced compared with wild conspecific plants (Kushad et al. 1999; Rosa 1999; Moyes et al. 2000). Several studies have demonstrated that both herbivores and their parasitoids perform more poorly on wild than on cultivated brassicaceous plant species (Benrey et al. 1998; Harvey et al. 2007a; Gols et al. 2008c).

Resistance to and persistence of pesticides in the environment have promoted the search for alternative methods to control pests in agricultural systems. This has resulted in a wealth of studies investigating factors that improve the control of insect pests by the herbivore's natural enemies. Many studies in agroecological research assume that tritrophic interactions (e.g., plant-herbivore-parasitoid interactions) function similarly in managed and unmanaged ecosystems (Barbosa 1993). However, the validity of these assumptions has rarely been empirically tested. In a seminal paper, Root (1973) introduced the 'resource concentration' hypothesis, which states that specialised herbivores attain higher densities in monocultures, because they are more likely to find and remain on host plants that are growing in pure stands. Likewise, given that they evolved in more complex natural ecosystems, parasitoids are often less challenged in finding hosts in agricultural monocultures and frequently overexploit host populations in cropping systems. Furthermore, the resource concentration hypothesis may also apply to generalist herbivores as a consequence of reduced levels of allelochemicals. This may explain why generalist herbivores, such as the cabbage moth (Mamestra brassicae) are not easy to find in natural plant assemblages but often become abundant, damaging pests in cabbage fields. Comparison of the foraging behaviour and population dynamics of hosts and their parasitoids in managed agricultural and unmanaged natural ecosystems may provide new insights into the mechanisms underlying tritrophic interactions (e.g., Ohsaki and Sato 1999).

For many crop plant species it has been demonstrated that herbivore-damaged plants emit volatile compounds that are attractive to parasitoids (for examples of parasitoid attraction in the Brassicaceae, see Table 3) and some parasitoids can even discriminate between volatiles emitted by different cultivars of the same crop species (Geervliet et al. 1996; Liu and Jiang 2003). However, plant breeding aimed at specific traits may not only have changed levels of nutrients and GS but also the quality and/or quantity of volatile blends produced in response to feeding damage. Volatile GS hydrolysis products in the headspace in cultivars of $B$. oleracea have been demonstrated to be very low (Blaakmeer et al. 1994; Geervliet et al. 1997; Bukovinszky et al. 2005). It would be interesting to analyse and quantify HIPV emissions and their attractiveness to parasitoids in wild $B$. oleracea populations in which foliar GS have been reported to be much higher than in cultivated strains.

Specialist herbivores have evolved efficient GS detoxification systems (Ratzka et al. 2002; Wittstock et al. 2004; Agerbirk et al. 2006) and larvae of these 
species may use GS as feeding stimulants (Renwick 2002). Consequently, the negative effects of GS on the performance of specialist herbivores are considered to be low. However, high GS concentrations may also affect negatively the development of specialist herbivores (Agrawal and Kurashige 2003). Therefore in natural plant populations where individual plants or populations contain high levels of GS, it is expected that the development of specialists may also be compromised. Finally, individual GS compounds may differ in their defence activity. Reduced levels of GS in cultivated Brassicaceae may lead to underestimations in the adverse effects of GS when compared with wild conspecifics, in which levels of toxic secondary plant compounds have not been modified.

\section{Arabidopsis and herbivore-parasitoid interactions}

The model plant $A$. thaliana has been used for a wide range of research topics such as plant development, pathogen resistance and secondary plant metabolite chemistry. As a member of the Brassicaceae, Arabidopsis also synthesises GS. At present, the elucidation of pathways involved in the biosynthesis of GS, especially aliphatic GS, relies substantially on research with Arabidopsis (Halkier and Gershenzon 2006). Since GS hydrolysis products play a role in plant defence against insects, the effects of GS on herbivore performance have recently been studied using different genotypes/mutants of this plant species (Stotz et al. 2000; Lambrix et al. 2001; Kliebenstein et al. 2002; Burow et al. 2006). For example, Burow et al. (2006) and Kliebenstein et al. (2002) investigated the effect of an epithiospecifier protein (EPS) on the performance of generalist and specialist lepidopteran herbivores. This ESP generates the production of nitriles instead of the more toxic isothiocyanates. This raises the question as to why a plant would redirect its defence chemistry and become more susceptible to insect herbivory. Burow et al. (2006) suggest that the expression of ESP genes may play a role against other attackers such as pathogens, or else plants expressing ESP may be more attractive to insect parasitoids. An alternative explanation for the existence of ESP could be that selection against the adverse effects of ESP expression is very low in Arabidopsis populations. Arabidopsis is a winter annual, which starts to flower in March and completes its development in April to early May. Most potential herbivores, such as $P$. rapae, usually first appear in April and May when Arabidopsis plants are fully seeded and when the plant's vegetative tissues have disappeared. A temporal mismatch between the phenology of Arabidopsis and insect herbivores such as $P$. rapae suggests that we should interpret the adaptive significance of defensive traits in this plant with some caution (Yano 1994; Arany et al. 2005; Harvey et al. 2007b). Defensive traits in Arabidopsis may be phylogenetically conserved in the genome, and there may be little cost in maintaining them.

The availability of many mutant and transgenic lines has extended the study of indirect defences (i.e., the production of plant volatiles that attract natural enemies of insect herbivores) to Arabidopsis. Similar to other brassicaceous plant species, Arabidopsis emits volatile chemicals in response to herbivore feeding that are attractive to parasitoids (van Poecke et al. 2001, 2003; Girling et al. 2006). Genes from major biosynthetic pathways are induced in response to $P$. rapae feeding (van Poecke et al. 2001). These genes include AtTPS10, AtPAL1, AtLOX2, AtHPL, and AtAOS. AtTPS10 is a terpenoid synthase involved in myrcene production and AtPALI encodes phenylalanine ammonia-lyase, which plays a role in methyl salicylate production. AtLOX2 and AtHPL, encoding lipoxygenase and hydroperoxide lyase, respectively, are important for the production of green leaf volatiles $\left(\mathrm{C}_{6}\right.$ alcohols, aldehydes and esters). AtAOS encodes allene oxide synthase. Both AtAOS and AtLOX2 play a role in the production of jasmonic acid, a plant hormone that plays an important role in induced direct and indirect plant defence responses (Karban and Baldwin 1997). Arabidopsis mutants were used to elucidate signal transduction pathways and the role of the hormones jasmonic acid and salicylic acid in induced indirect plant defences (van Poecke and Dicke 2002). Mutants of this plant species that were impaired in the octadecanoid and salicylic pathway were less attractive to the parasitoid C. glomerata than wild-type plants. Transgenic lines with enhanced hydroperoxide lyase (HPL) activity produced more (Z)-3-hexanal when damaged by $P$. rapae and were more attractive to $C$. glomerata than wild-type Arabidopsis plants (Shiojiri et al. 2006b). An Arabidopsis mutant (all84), in which the production of (Z)-3-hexanal was suppressed, attracted fewer $C$. glomerata females when damaged by $P$. rapae than wild-type plants (Shiojiri et al. 
2006a). Moreover, C. glomerata females were also attracted to synthetic green leaf volatiles (Shiojiri et al. 2006a). Contrastingly, C. plutellae Kurdjumov (now $C$. vestalis Haliday) females did not discriminate between all84 and wild type plants when damaged by its host P. xylostella (Shiojiri et al. 2006a). These results suggest that the relative importance of green leaf volatiles as parasitoid attractants is species-specific.

Mutant and transgenic lines of A. thaliana can be used to investigate the relative role of volatile chemicals as natural enemy attractants. However, results should be verified using the plant species on which these herbivores and their parasitoids naturally occur. In addition, although many studies have reported on parasitoid attraction to herbivore-induced A. thaliana volatiles, only one has examined the quality of the host for the parasitoid when reared on Arabidopsis (Barker et al. 2007). In this study, adult C. plutellae were significantly smaller when the host, P. xylostella, was reared on A. thaliana, than when the host was reared on B. rapa.

\section{Future directions}

As we have shown in this review, relatively few studies have investigated the effects of secondary plant chemistry mediated through the host on parasitoid performance (see also Harvey 2005; Ode 2006). To understand the relative importance of bottom-up and top-down control of insect herbivores it is important to also study bottom-up effects of plant chemistry on the interactions between herbivores and their natural enemies. Here we have reported studies showing that herbivores and their parasitoids are differentially affected by the herbivore's food plant and that wild brassicaceous plant species tend to be more toxic than cultivated strains or species. Very few studies have actually shown that GS hydrolysis products result in reduced development of the herbivore (Agrawal and Kurashige 2003). The compartmentalised myrosinase-GS defence in the Brassicaceae complicates empirical testing of the adverse effects of GS. Since the biosynthesis of aliphatic GS is well-studied, the effect of GS on insect herbivores and their parasitoids is mainly restricted to aliphatic GS (GS derived from methionine) and to a lesser extent the aromatic GS (GS derived from phenylalanine). Indole GS, which are derived from tryptophan, could also play a role in defence against insects (Soler et al. 2007a; Gols et al. 2008c; Agerbirk et al. 2008). In addition, differences in the expression of myrosinase enzymes, which catalyze hydrolysis of GS, could differ among plants species and populations and affect herbivore and parasitoid performance ( $\mathrm{Li}$ et al. 2000; Müller and Sieling 2006). Insect growth and development also depend on the availability of primary metabolites such as amino acids as well as nutrients such as nitrogen that are often limiting. It is likely that levels of primary metabolites vary among plants species. Artificial diets (Agrawal and Kurashige 2003), artificially selected lines (Mithen 1992; Li et al. 2000; Müller and Sieling 2006) or the use of mutant plants that have been modified to emphasise a single trait may help to better understand the relative effect of GS on insect performance, but one should also bear in mind the effect of other defence-related compounds as well as nutrients.

Little is known about the ability of parasitoids to detoxify allelochemicals (see also Ode 2006). The alimentary tract of endoparasitoid larvae is not externally connected until after egression and pupation, and thus any phytochemicals ingested during larval feeding must be stored until they are voided in by-products such as meconia and/or cocoon silk (Barbosa et al. 1986; Bowers 2003). Parasitoid larvae may have developed their own detoxification mechanism(s), or else they can tolerate high levels of allelochemicals and might even sequester them. Some studies have investigated the detoxification of GS in predators of insect herbivores. Feeding on M. persicae and $\mathrm{Br}$. brassicae induced glutathione S-tranferase activity in the hoverfly E. balteatus (Vanhaelen et al. 2001). Glutathione S-tranferase is an important detoxification enzyme in eukaryotes. Other enzymes such as cytochrome P450's can also metabolise xenobiotics and could play a role in detoxification of plant-derived allelochemicals. The effect of GS and other allelochemicals on physiological traits of parasitoids is also virtually unknown. In particular, it would be interesting to determine what effects (if any) GS in the host's diet have on the ability of parasitoids to utilise resources for maintenance and reproduction (Jervis et al. 2008).

The majority of studies investigating the attractiveness of HIPV to parasitoids are based on 
windtunnel or Y-tube olfactometer experiments, mainly using crop plant species (Table 3) (for a critical review see Hunter 2002). However, little is known about the spatial scale at which these plant volatiles are perceived by parasitoids in the field. Moreover, in natural habitats parasitoids have to forage in complex environments that may consist of many different plant species where there are structural and chemical barriers. The foraging behaviour of parasitoids has been demonstrated to be affected by the structure and identity of the local plant community (Gols et al. 2005; Bukovinszky et al. 2007). In addition, individual foraging decisions do not necessarily translate directly into differences in population dynamics. For example, parasitism rates by $C$. plutellae differed when the parasitoids were reared on two different host plants in short-term experiments, but in long-term experiments the population dynamics were similar on both host plant species (Karimzadeh et al. 2004). Field studies are thus necessary to reveal the relative importance of HIPV on plant/parasitoid fitness in both managed agricultural and unmanaged natural ecosystems (Geervliet et al. 2000).

One other area that is understudied is the degree of local adaptation exhibited by herbivore and natural enemy populations to different crucifer species that grow in their habitats. This is especially important in understanding how consumers respond to invasive plants, given that several species in the Brassicaceae are considered to be highly invasive pests in North America and Europe (Dietz et al. 1999; Meekins and McCarthy 1999; Lankau and Strauss 2007). Recent empirical evidence suggests that plants with novel secondary chemistries have the capacity to invade new regions because the local herbivore populations are not adapted to them (Cappuccino and Carpenter 2005; Keeler et al. 2006; Callaway and Vivanco 2007; Müller this issue-b). Furthermore, studies with invasive plants have rarely included natural enemies of herbivores associated with these plants. Studies with invasive crucifers offer an excellent opportunity for understanding mechanisms underlying novel interactions, and how other processes such as 'ecological fitting' (Agosta 2006) may determine the success of insects associated with invasive plants.

In this review we have focused on the effect of the host's food plant and on the effects of plant volatile emissions on the development and behaviour of insect parasitoids and predators. In most cases, these two plant defence strategies have been studied independently. However direct and indirect defences may not act independently from each other and this may impose an evolutionary 'dilemma' or 'conflict' when a female parasitoid is attracted to a plant that negatively influences the development of her progeny (Dicke 1999b; Havill and Raffa 2000; Hunter 2003). Future research should consider this potentially important conflict when studying the evolution of plant defences against insect herbivory.

Acknowledgements We would like to thank Caroline Müller for the invitation to write this review and Marcel Dicke for giving constructive comments on draft versions of this paper.

Open Access This article is distributed under the terms of the Creative Commons Attribution Noncommercial License which permits any noncommercial use, distribution, and reproduction in any medium, provided the original author(s) and source are credited.

\section{References}

Agelopoulos NG, Keller MA (1994a) Plant natural enemy association in the tritrophic system Cotesia rubeculaPieris rapae-Brassicaceae (Cruciferae): II. Preference of C. rubecula for landing and searching. J Chem Ecol 20:1735-1748. doi:10.1007/BF02059895

Agelopoulos NG, Keller MA (1994b) Plant natural enemy association in the tritrophic system, Cotesia rubeculaPieris rapae-Brassiceae (Cruciferae): I. Sources of infochemicals. J Chem Ecol 20:1725-1734. doi:10.1007/ BF02059894

Agelopoulos NG, Dicke M, Posthumus MA (1995) Role of volatile infochemicals emitted by feces of larvae in hostsearching behavior of parasitoid Cotesia rubecula (Hymenoptera: Braconidae): a behavioral and chemical study. J Chem Ecol 21:1789-1811. doi:10.1007/ BF02033677

Agerbirk N, Müller C, Olsen CE, Chew FS (2006) A common pathway for metabolism of 4-hydroxybenzylglucosinolate in Pieris and Anthocaris (Lepidoptera: Pieridae). Biochem Syst Ecol 34:189-198. doi:10.1016/j.bse.2005.09.005

Agerbirk A, de Vos H, Kim JH, Jander G (2008) Indole glucosinolates breakdown products and its biological effects. Phytochem Rev. doi:10.1007/s11101-008-9098-0

Agosta SJ (2006) On ecological fitting, plant-insect associations, herbivore host shifts, and host plant selection. Oikos 114:556-565. doi:10.1111/j.2006.0030-1299.15025.x

Agrawal AA (1999) Induced plant defense: evolution of induction and adaptive phenotypic plasticity. In: Agrawal AA, Tuzun S, Bent E (eds) Induced plant defenses against pathogens and herbivores. Biochemistry, ecology and agriculture. APS Press, St. Paul, pp 251-268 
Agrawal AA, Kurashige NS (2003) A role for isothiocyanates in plant resistance against the specialist herbivore Pieris rapae. J Chem Ecol 29:1403-1415. doi:10.1023/A: 1024265420375

Aliabadi A, Renwick JAA, Whitman DW (2002) Sequestration of glucosinolates by harlequin bug Murgantia histrionica. J Chem Ecol 28:1749-1762. doi:10.1023/A:1020 505016637

Aplin RT, Darcyward R, Rothschild M (1975) Examination of Large White and Small White butterflies (Pieris spp.) for presence of mustard oils and mustard oil glycosides. J Entomol Ser A 50:73-78

Arany AM, de Jong TJ, van der Meijden E (2005) Herbivory and abiotic factors affect population dynamics of Arabidopsis thaliana in a sand dune area. Plant Biol 7:549555. doi:10.1055/s-2005-865831

Arimura GI, Garms S, Maffei M, Bossi S, Schulze B, Leitner $M$ et al (2008) Herbivore-induced terpenoid emission in Medicago truncatula: concerted action of jasmonate, ethylene and calcium signaling. Planta 227:453-464. doi: 10.1007/s00425-007-0631-y

Barbosa P (1993) Lepidopteran foraging on plants in agroecosysems: constraints and consequences. In: Stamp NE, Casey TM (eds) Caterpillars: ecological and evolutionary constraints on foraging. Chapman and Hall, New York, pp 523-566

Barbosa P, Saunders JA, Kemper J, Trumbule R, Olechno J, Martinat P (1986) Plant allelochemicals and insect parasitoids: effects of nicotine on Cotesia congregata (Say) (Hymenoptera, Braconidae) and Hyposoter annulipes (Cresson) (Hymenoptera, Ichneumonidae). J Chem Ecol 12:1319-1328. doi:10.1007/BF01012351

Barker JE, Poppy GM, Payne CC (2007) Suitability of Arabidopsis thaliana as a model for host plant-Plutella xylostella-Cotesia plutellae interactions. Entomol Exp Appl 122:17-26. doi:10.1111/j.1570-7458.2006.00459.x

Benrey B, Denno RF (1997) The slow-growth-high-mortality hypothesis: a test using the cabbage butterfly. Ecology 78:987-999

Benrey B, Denno RF, Kaiser L (1997) The influence of plant species on attraction and host acceptance in Cotesia glomerata (Hymenoptera: Braconidae). J Insect Behav 10:619-630. doi:10.1007/BF02765382

Benrey B, Callejas A, Rios L, Oyama K, Denno RF (1998) The effects of domestication of Brassica and Phaseolus on the interaction between phytophagous insects and parasitoids. Biol Control 11:130-140. doi:10.1006/bcon.1997.0590

Bezemer TM, van Dam NM (2005) Linking aboveground and belowground interactions via induced plant defenses. Trends Ecol Evol 20:617-624. doi:10.1016/j.tree.2005. 08.006

Blaakmeer A, Geervliet JBF, van Loon JJA, Posthumus MA, van Beek TA, de Groot A (1994) Comparative headspace analysis of cabbage plants damaged by two species of Pieris caterpillars: consequences for in-flight host location by Cotesia parasitoids. Entomol Exp Appl 73:175-182. doi:10.1007/BF02383424

Blande JD, Pickett JA, Poppy GM (2004) Attack rate and success of the parasitoid Diaeretiella rapae on specialist and generalist feeding aphids. J Chem Ecol 30:17811795. doi:10.1023/B:JOEC.0000042401.52088.54
Blande JD, Pickett JA, Poppy GM (2007) A comparison of semiochemically mediated interactions involving specialist and generalist Brassica-feeding aphids and the braconid parasitoid Diaeretiella rapae. J Chem Ecol 33:767-779. doi:10.1007/s10886-007-9264-7

Blau PA, Feeny P, Contardo L, Robson DS (1978) Allylglucosinolate and herbivorous caterpillars: a contrast in toxicity and tolerance. Science 200:1296-1298. doi: 10.1126/science.200.4347.1296

Bottrell DG, Barbosa P, Gould F (1998) Manipulating natural enemies by plant variety selection and modification: a realistic strategy? Annu Rev Entomol 43:347-367. doi: 10.1146/annurev.ento.43.1.347

Bowers MD (2003) Hostplant suitability and defensive chemistry of the Catalpa sphinx, Ceratomia catalpae. J Chem Ecol 29:2359-2367. doi:10.1023/A:1026234716785

Bradburne RP, Mithen R (2000) Glucosinolate genetics and the attraction of the aphid parasitoid Diaeretiella rapae to Brassica. Proc R Soc Lond B Biol Sci 267:89-95. doi: 10.1098/rspb.2000.0971

Bridges M, Jones AME, Bones AM, Hodgson C, Cole R, Bartlet E et al (2002) Spatial organization of the glucosinolate-myrosinase system in brassica specialist aphids is similar to that of the host plant. Proc R Soc Lond B Biol Sci 269:187-191. doi:10.1098/rspb.2001.1861

Bukovinszky T, Gols R, Posthumus MA, Vet LEM, van Lenteren JC (2005) Variation in plant volatiles and attraction of the parasitoid Diadegma semiclausum (Hellen). J Chem Ecol 31:461-480. doi:10.1007/s10886005-2019-4

Bukovinszky T, Gols R, Hemerik L, Van Lenteren JC, Vet LEM (2007) Time allocation of a parasitoid foraging in heterogeneous vegetation: implications for host-parasitoid interactions. J Anim Ecol 76:845-853. doi:10.1111/ j.1365-2656.2007.01259.x

Burow M, Müller C, Gershenzon J, Wittstock U (2006) Altered glucosinolate hydrolysis in genetically engineered Arabidopsis thaliana and its influence on the larval development of Spodoptera littoralis. J Chem Ecol 32:2333-2349. doi:10.1007/s10886-006-9149-1

Callaway RM, Vivanco JM (2007) Invasion of plants into native communities using the underground information superhighway. Allelopath J 19:143-151

Cappuccino N, Carpenter D (2005) Invasive exotic plants suffer less herbivory than non-invasive exotic plants. Biol Lett-UK 1:435-438. doi:10.1098/rsbl.2005.0341

Chew FS (1988) Biological effects of glucosinolates. In: Cutler HG (ed) Biologically active natural products for potential use in agriculture. American Chemical Society, Washington, pp 155-181

de Boer JG, Dicke M (2004) The role of methyl salicylate in prey searching behavior of the predatory mite Phytoseiulus persimilis. J Chem Ecol 30:255-271. doi:10.1023/B: JOEC.0000017976.60630.8c

de Boer JG, Posthumus MA, Dicke M (2004) Identification of volatiles that are used in discrimination between plants infested with prey or nonprey herbivores by a predatory mite. J Chem Ecol 30:2215-2230. doi:10.1023/B:JOEC. $0000048784.79031 .5 \mathrm{e}$

Dicke M (1999a) Are herbivore-induced plant volatiles reliable indicators of herbivore identity to foraging carnivorous 
arthropods? Entomol Exp Appl 91:131-142. doi: 10.1023/A:1003608019062

Dicke M (1999b) Direct and indirect effects of plants on performance of beneficial organisms. In: Ruberson JR (ed) Handbook of pest management. New York, pp 105-153

Dicke M, van Poecke RMP (2002) Signalling in plant-insect interactions: signal transduction in direct and indirect plant defence. In: Scheel D, Wasternack C (eds) Plant signal transduction. University Press, Oxford, pp 289-316

Dicke M, van Beek TA, Posthumus MA, Ben Dom N, van Bokhoven H, de Groot AE (1990) Isolation and identification of volatile kairomone that affects acarine predatorprey interactions: involvement of host plant in its production. J Chem Ecol 16:381-396. doi:10.1007/BF0 1021772

Dietz H, Steinlein T, Ullmann I (1999) Establishment of the invasive perennial herb Bunias orientalis L.: an experimental approach. Acta Oecol 20:621-632. doi: 10.1016/S1146-609X(99)00104-6

Fatouros NE, Van Loon JJA, Hordijk KA, Smid HM, Dicke M (2005) Herbivore-induced plant volatiles mediate in-flight host discrimination by parasitoids. J Chem Ecol 31:20332047. doi:10.1007/s10886-005-6076-5

Feeny P (1977) Defensive ecology of Cruciferae. Ann Mo Bot Gard 64:221-234. doi:10.2307/2395334

Fox LR, Letourneau DK, Eisenbach J, Vannouhuys S (1990) Parasitism rates and sex ratios of a parasitoid wasp: effects of herbivore and plant quality. Oecologia 83: 414-419

Fox LR, Kester KM, Eisenbach J (1996) Direct and indirect responses of parasitoids to plants: sex ratio, plant quality and herbivore diet breadth. Entomol Exp Appl 80: 289-292. doi:10.1007/BF00194777

Francis F, Lognay G, Wathelet JP, Haubruge E (2001a) Effects of allelochemicals from first (Brassicaceae) and second (Myzus persicae and Brevicoryne brassicae) trophic levels on Adalia bipunctata. J Chem Ecol 27:243-256. doi: 10.1023/A:1005672220342

Francis F, Haubruge E, Hastir P, Gaspar C (2001b) Effect of aphid host plant on development and reproduction of the third trophic level, the predator Adalia bipunctata (Coleoptera: Coccinellidae). Environ Entomol 30:947-952

Geervliet JBF, Vet LEM, Dicke M (1994) Volatiles from damaged plants as major cues in long-range host-searching by the specialist parasitoid Cotesia rubecula. Entomol Exp Appl 73:289-297. doi:10.1007/BF02382480

Geervliet JBF, Vet LEM, Dicke M (1996) Innate responses of the parasitoids Cotesia glomerata and C. rubecula (Hymenoptera: Braconidae) to volatiles from different plant-herbivore complexes. J Insect Behav 9:525-538. doi:10.1007/BF02213877

Geervliet JBF, Posthumus MA, Vet LEM, Dicke M (1997) Comparative analysis of headspace volatiles from different caterpillar-infested or uninfested food plants of Pieris species. J Chem Ecol 23:2935-2954. doi:10.1023/A: 1022583515142

Geervliet JBF, Vreugdenhil AI, Dicke M, Vet LEM (1998) Learning to discriminate between infochemicals from different plant-host complexes by the parasitoids Cotesia glomerata and C. rubecula. Entomol Exp Appl 86:241252. doi:10.1023/A:1003186706517
Geervliet JBF, Verdel MSW, Snellen H, Schaub J, Dicke M, Vet LEM (2000) Coexistence and niche segregation by field populations of the parasitoids Cotesia glomerata and C. rubecula in the Netherlands: predicting field performance from laboratory data. Oecologia 124:55-63. doi: $10.1007 / \mathrm{s} 004420050024$

Girling RD, Hassall M, Turner JG, Poppy GM (2006) Behavioural responses of the aphid parasitoid Diaeretiella rapae to volatiles from Arabidopsis thaliana induced by Myzus persicae. Entomol Exp Appl 120:1-9. doi:10.1111/j. 1570-7458.2006.00423.x

Godfray HCJ (1994) Parasitoids. Behavioral and evolutionary ecology. Princeton University Press, Princeton

Gols R, Bukovinszky T, Hemerik L, Harvey JA, Van Lenteren JC, Vet LEM (2005) Reduced foraging efficiency of a parasitoid under habitat complexity: implications for population stability and species coexistence. J Anim Ecol 74:1059-1068. doi:10.1111/j.1365-2656.2005.01003.x

Gols R, Raaijmakers CE, Van Dam NM, Dicke M, Bukovinszky T, Harvey JA (2007) Temporal changes affect plant chemistry and tritrophic interactions. Basic Appl Ecol 8:421-433. doi:10.1016/j.baae.2006.09.005

Gols R, Bukovinszky T, Van Dam NM, Dicke M, Bullock JM, Harvey JA (2008a) Performance of generalist and specialist herbivores and their endoparasitoids differs on cultivated and wild Brassica populations. J Chem Ecol 34:132-143. doi:10.1007/s10886-008-9429-z

Gols R, Witjes LMA, van Loon JJA, Posthumus MA, Dicke M, Harvey JA (2008b) The effect of direct and indirect defenses in two wild brassicaceous plant species on a specialist herbivore and its gregarious endoparasitoid. Entomol Exp Appl 128:99-108

Gols R, Wagenaar R, Bukovinszky T, Van Dam NM, Dicke M, Bullock JM et al (2008c) Genetic variation in defence chemistry in wild cabbages affects herbivores and their endoparasitoids. Ecology 89:1616-1626. doi:10.1890/070873.1

Halitschke R, Stenberg JA, Kessler D, Kessler A, Baldwin IT (2008) Shared signals - 'alarm calls' from plants increase apparency to herbivores and their enemies in nature. Ecol Lett 11:24-34

Halkier BA, Gershenzon J (2006) Biology and biochemistry of glucosinolates. Annu Rev Plant Biol 57:303-333. doi: 10.1146/annurev.arplant.57.032905.105228

Harvey JA (2005) Factors affecting the evolution of development strategies in parasitoid wasps: the importance of functional constraints and incorporating complexity. Entomol Exp Appl 117:1-13. doi:10.1111/j.1570-7458. 2005.00348.x

Harvey JA, Strand MR (2002) The developmental strategies of endoparasitoid wasps vary with host feeding ecology. Ecology 83:2439-2451

Harvey JA, Wagenaar R (2006) Development of the herbivore Pieris rapae and its endoparasitoid Cotesia rubecula on crucifers of field edges. J Appl Entomol 130:465-470. doi:10.1111/j.1439-0418.2006.01093.x

Harvey JA, van Dam NM, Gols R (2003) Interactions over four trophic levels: foodplant quality affects development of a hyperparasitoid as mediated through a herbivore and its primary parasitoid. J Anim Ecol 72:520-531. doi:10.1046/ j.1365-2656.2003.00722.x 
Harvey JA, Gols R, Wagenaar R, Bezemer TM (2007a) Development of an insect herbivore and its pupal parasitoid reflect differences in direct plant defense. J Chem Ecol 33:1556-1569. doi:10.1007/s10886-007-9323-0

Harvey JA, Witjes LMA, Benkirane M, Duyts H, Wagenaar R (2007b) Nutritional suitability and ecological relevance of Arabidopsis thaliana and Brassica oleracea as foodplants for the cabbage butterfly, Pieris rapae. Plant Ecol 189:117-126. doi:10.1007/s11258-006-9204-6

Havill NP, Raffa KF (2000) Compound effects of induced plant responses on insect herbivores and parasitoids: implications for tritrophic interactions. Ecol Entomol 25:171-179. doi:10.1046/j.1365-2311.2000.00247.x

Hopkins RJ, Ekbom B, Henkow L (1998) Glucosinolate content and susceptibility for insect attack of three populations of Sinapis alba. J Chem Ecol 24:1203-1216. doi:10.1023/A:1022498903175

Hunter MD (2002) A breath of fresh air: beyond laboratory studies of plant volatile-natural enemy interactions. Agric For Entomol 4:81-86. doi:10.1046/j.1461-9563.2002. 00138.x

Hunter MD (2003) Effects of plant quality on the population ecology of parasitoids. Agric For Entomol 5:1-8. doi: 10.1046/j.1461-9563.2003.00168.x

Jervis MA, Ellers J, Harvey JA (2008) Resource acquisition, allocation, and utilization in parasitoid reproductive strategies. Annu Rev Entomol 53:361-385. doi:10.1146/ annurev.ento.53.103106.093433

Karban R, Baldwin IT (1997) Induced responses to herbivory. University of Chicago Press, Chicago

Karimzadeh J, Wright DJ (2008) Bottom-up cascading effects in a tritrophic system: interactions between plant quality and host-parasitoid immune responses. Ecol Entomol 33:45-52

Karimzadeh J, Bonsall MB, Wright DJ (2004) Bottom-up and top-down effects in a tritrophic system: the population dynamics of Plutella xylostella (L.)-Cotesia plutellae (Kurdjumov) on different host plants. Ecol Entomol 29:285-293. doi:10.1111/j.0307-6946.2004.00609.x

Karowe DN, Schoonhoven LM (1992) Interactions among three trophic levels: the influence of host plant on performance of Pieris brassicae and its parasitoid, Cotesia glomerata. Entomol Exp Appl 62:241-251. doi: 10.1007/BF00353443

Kazana E, Pope TW, Tibbles L, Bridges M, Pickett JA, Bones AM et al (2007) The cabbage aphid: a walking mustard oil bomb. Proc R Soc Lond B Biol Sci 274:2271-2277. doi: 10.1098/rspb.2007.0237

Keeler MS, Chew FS, Goodale BC, Reed JM (2006) Modelling the impacts of two exotic invasive species on a native butterfly: top-down vs. bottom-up effects. J Anim Ecol 75:777-788. doi:10.1111/j.1365-2656.2006.01098.x

Kliebenstein D, Pedersen D, Barker B, Mitchell-Olds T (2002) Comparative analysis of quantitative trait loci controlling glucosinolates, myrosinase and insect resistance in Arabidapsis thaliana. Genetics 161:325-332

Kushad MM, Brown AF, Kurilich AC, Juvik JA, Klein BP, Wallig MA et al (1999) Variation of glucosinolates in vegetable crops of Brassica oleracea. J Agric Food Chem 47:1541-1548. doi:10.1021/jf980985s
Lambrix V, Reichelt M, Mitchell-Olds T, Kliebenstein DJ, Gershenzon J (2001) The Arabidopsis epithiospecifier protein promotes the hydrolysis of glucosinolates to nitriles and influences Trichoplusia ni herbivory. Plant Cell 13:2793-2807

Lankau RA, Strauss SY (2007) Mutual feedbacks maintain both genetic and species diversity in a plant community. Science 317:1561-1563. doi:10.1126/science.1147455

Li Q, Eigenbrode SD, Stringham GR, Thiagarajah MR (2000) Feeding and growth of Plutella xylostella and Spodoptera eridania on Brassica juncea with varying glucosinolate concentrations and myrosinase activities. J Chem Ecol 26:2401-2419. doi:10.1023/A:1005535129399

Liu SS, Jiang LH (2003) Differential parasitism of Plutella xylostella (Lepidoptera: Plutellidae) larvae by the parasitoid Cotesia plutellae (Hymenoptera: Braconidae) on two host plant species. Bull Entomol Res 93:65-72. doi: 10.1079/BER2002208

Masters GJ, Brown VK (1997) Host-plant mediated interactions between spatially separated herbivores: effects on community structure. In: Gange AC, Brown VK (eds) Multitrophic interactions in terrestrial systems. Blackwell Science, Oxford, pp 217-235

Mattiacci L, Dicke M, Posthumus MA (1994) Induction of parasitoid attracting synomone in Brussels sprouts plants by feeding of Pieris brassicae larvae-role of mechanical damage and herbivore elicitor. J Chem Ecol 20:22292247. doi:10.1007/BF02033199

Mattiacci L, Dicke M, Posthumus MA (1995) $\beta$-Glucosidase: an elicitor of herbivore-induced plant odor that attracts host-searching parasitic wasps. Proc Natl Acad Sci USA 92:2036-2040. doi:10.1073/pnas.92.6.2036

Meekins JF, McCarthy BC (1999) Competitive ability of Alliaria petiolata (garlic mustard, Brassicaceae), an invasive, nonindigenous forest herb. Int $\mathrm{J}$ Plant Sci 160:743-752. doi: $10.1086 / 314156$

Mithen R (1992) Leaf glucosinolate profiles and their relationship to pest and disease resistance in oilseed rape. Euphytica 63:71-83. doi:10.1007/BF00023913

Mithen R (2001) Glucosinolates: biochemistry, genetics and biological activity. Plant Growth Regul 34:91-103. doi: 10.1023/A:1013330819778

Mithen R, Raybould AF, Giamoustaris A (1995) Divergent selection for secondary metabolites between wild populations of Brassica oleracea and its implications for plant-herbivore interactions. Heredity 75:472-484. doi: 10.1038/hdy.1995.164

Moyes CL, Collin HA, Britton G, Raybould AE (2000) Glucosinolates and differential herbivory in wild populations of Brassica oleracea. J Chem Ecol 26:2625-2641. doi:10.1023/A:1005549115751

Müller C (this issue-a) Interactions between plants containing glucosinolates and myrosinases and the sawfly Athalia rosae. Phytochem Rev

Müller C (this issue-b) Role of glucosinolates in plant invasiveness. Phytochem Rev

Müller C, Brakefield PM (2003) Analysis of a chemical defense in sawfly larvae: easy bleeding targets predatory wasps in late summer. J Chem Ecol 29:2683-2694. doi: 10.1023/B:JOEC.0000008012.73092.01 
Müller C, Sieling N (2006) Effects of glucosinolate and myrosinase levels in Brassica juncea on a glucosinolatesequestering herbivore-and vice versa. Chemoecology 16:191-201. doi:10.1007/s00049-006-0347-7

Müller C, Agerbirk N, Olsen CE, Boevé JL, Schaffner U, Brakefield PM (2001) Sequestration of host plant glucosinolates in the defensive hemolymph of the sawfly Athalia rosae. J Chem Ecol 27:2505-2516. doi:10.1023/ A:1013631616141

Müller C, Boevé JL, Brakefield P (2002) Host plant derived feeding deterrence towards ants in the turnip sawfly Athalia rosae. Entomol Exp Appl 104:153-157. doi: 10.1023/A:1021202929313

Müller C, Agerbirk N, Olsen CE (2003) Lack of sequestration of host plant glucosinolates in Pieris rapae and P. brassicae. Chemoecology 13:47-54. doi:10.1007/ s000490300005

Ode PJ (2006) Plant chemistry and natural enemy fitness: effects on herbivore and natural enemy interactions. Annu Rev Entomol 51:163-185. doi:10.1146/annurev.ento. 51.110104.151110

Ohara Y, Takafuji A, Takabayashi J (2003a) Response to hostinfested plants in females of Diadegma semiclausum Hellen (Hymenoptera: Ichneumonidae). Appl Entomol Zool (Jpn) 38:157-162. doi:10.1303/aez.2003.157

Ohara Y, Takafuji A, Takabayashi J (2003b) Factors affecting the patch-leaving decision of the parasitic wasp Diadegma semiclausum (Hymenoptera: Ichneumonidae). Appl Entomol Zool (Jpn) 38:211-214. doi:10.1303/aez. 2003.211

Ohsaki N, Sato Y (1999) The role of parasitoids in evolution of habitat and larval food plant preference by three Pieris butterflies. Res Popul Ecol (Kyoto) 41:107-119. doi: 10.1007/PL00011975

Pinto DM, Nerg AM, Holopainen JK (2007) The role of ozonereactive compounds, terpenes, and green leaf volatiles (GLVs), in the orientation of Cotesia plutellae. J Chem Ecol 33:2218-2228. doi:10.1007/s10886-007-9376-0

Potting RPJ, Poppy GM, Schuler TH (1999) The role of volatiles from cruciferous plants and pre-flight experience in the foraging behaviour of the specialist parasitoid Cotesia plutellae. Entomol Exp Appl 93:87-95. doi: 10.1023/A: 1003822208843

Rask L, Andreasson E, Ekbom B, Eriksson S, Pontoppidan B, Meijer J (2000) Myrosinase: gene family evolution and herbivore defense in Brassicaceae. Plant Mol Biol 42:93113. doi:10.1023/A:1006380021658

Ratzka A, Vogel H, Kliebenstein DJ, Mitchell-Olds T, Kroymann J (2002) Disarming the mustard oil bomb. Proc Natl Acad Sci USA 99:11223-11228. doi:10.1073/pnas. 172112899

Rayor LS, Mooney LJ, Renwick JA (2007) Predatory behavior of Polistes dominulus wasps in response to cardenolides and glucosinolates in Pieris napi caterpillars. J Chem Ecol 33:1177-1185. doi:10.1007/s10886-007-9283-4

Read DP, Feeny PP, Root RB (1970) Habitat selection by the aphid parasite Diaeretiella rapae (Hymenoptera: Braconidae) and hyperparasite Charips brassicae (Hymenoptera: Cynipidae). Can Entomol 102:1567-1578

Renwick JAA (2001) Variable diets and changing taste in plant-insect relationships. J Chem Ecol 27:1063-1076
Renwick JAA (2002) The chemical world of crucivores: lures, treats and traps. Entomol Exp Appl 104:35-42. doi: 10.1023/A:1021231732022

Roßbach A, Löhr B, Vidal S (2005) Generalism versus specialism: responses of Diadegma mollipla (Holmgren) and Diadegma semiclausum (Hellen), to the host shift of the diamondback moth (Plutella xylostella L.) to peas. J Insect Behav 18:491-503. doi:10.1007/s10905-0055607-9

Root RB (1973) Organization of a plant-arthropod association in simple and diverse habitats: the fauna of collards (Brassica oleracea). Ecol Monogr 43:95-120. doi: $10.2307 / 1942161$

Rosa EAS (1999) Chemical composition. In: Gomez-Campo C (ed) Developments in plant genetics and breeding, 4. Biology of Brassica Coenospecies. Elsevier Science B.V., Amsterdam, pp 315-357

Rosenthal GA, Berenbaum MR (1992) Herbivores: their interactions with secondary plant metabolites. Academic Press, San Diego

Scascighini N, Mattiacci L, D'Alessandro M, Hern A, Rott AS, Dorn S (2005) New insights in analysing parasitoid attracting synomones: early volatile emission and use of stir bar sorptive extraction. Chemoecology 15:97-104. doi:10.1007/s00049-005-0300-1

Schoonhoven LM, van Loon JJA, Dicke M (2005) Insect-plant biology (2nd ed). Oxford University Press

Shiojiri K, Takabayashi J (2003) Effects of specialist parasitoids on oviposition preference of phytophagous insects: encounter-dilution effects in a tritrophic interaction. Ecol Entomol 28:573-578. doi:10.1046/j.1365-2311.2003.00539.x

Shiojiri K, Takabayashi J, Yano S, Takafuji A (2000) Flight response of parasitoids toward plant-herbivore complexes: a comparative study of two parasitoid-herbivore systems on cabbage plants. Appl Entomol Zool (Jpn) 35:87-92. doi:10.1303/aez.2000.87

Shiojiri K, Ozawa R, Matsui K, Kishimoto K, Kugimiya S, Takabayashi J (2006a) Role of the lipoxygenase/lyase pathway of host-food plants in the host searching behavior of two parasitoid species, Cotesia glomerata and Cotesia plutellae. J Chem Ecol 32:969-979. doi:10.1007/ s10886-006-9047-6

Shiojiri K, Kishimoto K, Ozawa R, Kugimiya S, Urashimo S, Arimura $G$ et al (2006b) Changing green leaf volatile biosynthesis in plants: an approach for improving plant resistance against both herbivores and pathogens. Proc Natl Acad Sci USA 103:16672-16676. doi: 10.1073/pnas.0607780103

Soler R, Bezemer TM, Van der Putten WH, Vet LEM, Harvey JA (2005) Root herbivore effects on above-ground herbivore, parasitoid and hyperparasitoid performance via changes in plant quality. J Anim Ecol 74:1121-1130. doi: 10.1111/j.1365-2656.2005.01006.x

Soler R, Bezemer TM, Cortesero AM, Van der Putten WH, Vet LEM, Harvey JA (2007a) Impact of foliar herbivory on the development of a root-feeding insect and its parasitoid. Oecologia 152:257-264. doi:10.1007/s00442-0060649-z

Soler R, Harvey JA, Kamp AFD, Vet LEM, Van der Putten WH, Van Dam NM et al (2007b) Root herbivores influence the behaviour of an aboveground parasitoid through 
changes in plant-volatile signals. Oikos 116:367-376. doi: 10.1111/j.0030-1299.2007.15501.x

Steinberg S, Dicke M, Vet LEM (1993) Relative importance of infochemicals from first and second trophic level in longrange host location by the larval parasitoid Cotesia glomerata. J Chem Ecol 19:47-59. doi:10.1007/ BF00987470

Stotz HU, Pittendrigh BR, Kroymann J, Weniger K, Fritsche J, Bauke A et al (2000) Induced plant defense responses against chewing insects: ethylene signaling reduces resistance of Arabidopsis against Egyptian cotton worm but not diamondback moth. Plant Physiol 124:1007-1017. doi: 10.1104/pp. 124.3.1007

Sznajder B, Harvey JA (2003) Second and third trophic level effects of differences in plant species reflect dietary specialisation of herbivores and their endoparasitoids. Entomol Exp Appl 109:73-82. doi:10.1046/j.1570-7458. 2003.00096.x

Takabayashi J, Sato Y, Horikoshi M, Yamaoka R, Yano S, Ohsaki N et al (1998) Plant effects on parasitoid foraging: differences between two tritrophic systems. Biol Control 11:97-103. doi:10.1006/bcon.1997.0583

Turlings TCJ, Benrey B (1998) Effects of plant metabolites on the behavior and development of parasitic wasps. Ecoscience 5:321-333

Turlings TCJ, Gouinguene S, Degen T, Fritzsche-Hoballah ME (2002) The chemical ecology of plant-caterpillar-parasitoid interactions. In: Tscharntke T, Hawkins BA (eds) Multitrophic level interactions. Cambridge University Press

van Dam NM, Tytgat J, Kirkegaard JA (2008) Root and shoot glucosinolates: a comparison of their diversity, function and interactions in natural and managed ecosystems. Phytochem Rev. doi:10.1007/s11101-008-9101-9

van Poecke RMP, Dicke M (2002) Induced parasitoid attraction by Arabidopsis thaliana: involvement of the octadecanoid and the salicylic acid pathway. J Exp Bot 53:1793-1799

van Poecke RMP, Posthumus MA, Dicke M (2001) Herbivoreinduced volatile production by Arabidopsis thaliana leads to attraction of the parasitoid Cotesia rubecula: chemical, behavioral, and gene-expression analysis. J Chem Ecol 27:1911-1928. doi:10.1023/A:1012213116515

van Poecke RMP, Roosjen M, Pumarino L, Dicke M (2003) Attraction of the specialist parasitoid Cotesia rubecula to Arabidopsis thaliana infested by host or non-host herbivore species. Entomol Exp Appl 107:229-236. doi: 10.1046/j.1570-7458.2003.00060.x

Vanhaelen N, Haubruge E, Lognay G, Francis F (2001) Hoverfly glutathione S-transferases and effect of Brassicaceae secondary metabolites. Pestic Biochem Physiol 71:170-177. doi:10.1006/pest.2001.2573

Vanhaelen N, Gaspar C, Francis F (2002) Influence of prey host plant on a generalist aphidophagous predator: Episyrphus balteatus (Diptera: Syrphidae). Eur J Entomol 99:561-564

Vlieger L, Brakefield PM, Müller C (2004) Effectiveness of the defence mechanism of the turnip sawfly, Athalia rosae (Hymenoptera: Tenthredinidae), against predation by lizards. Bull Entomol Res 94:283-289. doi:10.1079/ BER2004299

Vuorinen T, Nerg AM, Ibrahim MA, Reddy GVP, Holopainen JK (2004) Emission of Plutella xylostella-induced compounds from cabbages grown at elevated $\mathrm{CO} 2$ and orientation behavior of the natural enemies. Plant Physiol 135:1984-1992. doi:10.1104/pp.104.047084

Wiklund C, Järvi T (1982) Survival of distasteful insects after being attacked by naive birds: a reappraisal of the theory of aposematic coloration evolving through individual selection. Evol Int J Org Evol 36:998-1002. doi: $10.2307 / 2408077$

Wittstock U, Agerbirk N, Stauber EJ, Olsen CE, Hippler M, Mitchell-Olds T et al (2004) Successful herbivore attack due to metabolic diversion of a plant chemical defense. Proc Natl Acad Sci USA 101:4859-4864. doi: 10.1073/pnas.0308007101

Yano S (1994) Ecological and evolutionary interactions between wild crucifers and their herbivorous insects. Plant Species Biol 9:137-143. doi:10.1111/j.1442-1984.1994. tb00094.x 